\title{
The Scientific and Technological Support for Flower Production Village in Tianjin
}

\author{
Qiaoli Zhang \\ The science and Technology Department \\ Tianjin Agricultural University \\ Tianjin, China \\ 13512993618qlizhang@163.com
}

Chenguang Shi

Planning and Design Institute

Tianjin, China

e-mailshicg8512@sina.com

\author{
Jinghui Yang ${ }^{\mathrm{a}} *$ Maosi Wang ${ }^{\mathrm{b}}$ \\ The College of horticulture and landscape \\ Tianjin Agricultural University \\ Tianjin, China \\ a jinghuiyang2@aliyun.com \\ baosiwang1@163.com \\ Jingxin Zhang \\ Forestry Bureau in Jixian county of Tianjin \\ Tianjin, China \\ e-mail 563798598@qq.com
}

\begin{abstract}
In order to promote science and technology support, the support work was introduced in Jinghai and Jixian of Tianjin through practice of science and technology support in the village of flower production. The precision support measures were put forward such as finding out basic information, planning ahead and probable measures. The support experience was introduced including the team help, education support, "native" and "linkage" support. Finally, some suggestions were put forward in the poverty alleviation.
\end{abstract}

Keywords—science and technology support; Poverty alleviation; Practice; Experience

\section{INTRODUCTION}

The experts may guide farmer by science and technology and by the scientific development concept in order to increase their income and solve the livelihood as the basis, to speed up the pace for poverty reduction in the village $[1,2]$.

Science and technology support has become advancing rural route through the village driving by city and industry nurturing agriculture from the city development of China in recent years to narrow the gap between urban and rural areas and to realize well-off society in an all-round way [3-6].

In August 2013, the municipal committee and municipal government of CPC made a pair for helping difficult village. The experts in 236 municipal departments and units in Tianjin paired up with the farmers of 500 difficult villages in 10 districts and counties.

By 2015, the agricultural experts of science and technology amounted to 700 people. They carried on the connection of the scene, training, going into the village and family for instruction, network consulting regularly, helping more than $95 \%$ difficult villages, made about 200 agricultural feature films on practical technology and TV online course.

The 100 demonstration base were established, 300 applicable technologies were used. The system of science and technology research and development, introduction and service

We offer our thanks to Major scientific and technological projects in Tianjin Science and Technology Commission (Grant Number:

201502100) in the People's Republic of China. were formed to support key agricultural industry chain development.

To 2016, the difficult village economic development plan were made, formulated the "one village one policy" and guided by the experts from the municipal agricultural systems(school, ${ }^{1}$ office), Tianjin Agricultural University, Municipal Tourism Bureau, Municipal Women's Federation and other in 523 villages of Tianjin.

\section{ACCURATE SUPPORT}

\section{A. Clear Background}

Understanding the basic situation of the villages is the precondition of the "precise support". We investigated earnest on-the-spot in order to understand villages. The natural conditions (climate condition, soil condition, water resources present situation, the geological conditions), the population and land resources, production conditions, water conservancy facilities and equipment status), technology level (number of technical personnel, technical level), traffic conditions, market development present situation (flower production industry development level and pillar industries, the product of the market share, sales volume, sales price, sales, customers) of village, etc. were investigated by accessing to village farmers and village cadres, communicating and discussing with residency support group in village for many times, investigating to the local flower market, determining and analyzing of soil in the support village. In the end, the all basic information was understood, which laid a foundation for further work.

\section{B. Planning First}

Formulating appropriate support village planning, it is the key to the success of "precise support". Scientific planning is an important foundation for effective implementation of poverty alleviation work.

\footnotetext{
${ }^{1}$ We offer our thanks to Major scientific and technological
} 
The archives were established at first. A large number of relevant information was queried, the information was analyzed, current situation of the market, and the level of production technology was studied then through the "hownet", "read show academic search" to understand the causes of the poor village. We found that the sticking point of the slow development in the village was miscellaneous flower varieties, varieties of degradation, less good varieties (such as "new, strange, special varieties"), poor quality, and cultivation techniques lagged behind, which was unable to industrialize and commercialize production. Therefore, flower product can nearby sales less, low market price, quantity, poor efficiency.

We often discussed with the village leader, residency helping groups such as the first secretary of the village and communicated with experts in the municipal flower support team together repeatedly, found information and data, did feasibility verification again and again in order to scientific analysis, adjust measures according to local conditions for the establishment of good support in the village of development planning. In the end, the plan was written out with promoted multilateral consensus.

In planning, a real experience was that supporting new rural area was through the "government-led, farmer main body, social support". The government gave full play to the leading role. Farmers, their subject status were emphasized. We accepted to the opinions of the farmers, adhere to the peoplecentered concept, truly respect people, respect for the masses to participate, the right to know, to supervise and control. Our professional knowledge and understanding of the market and its forecast for the future development of integration was put into the planning. Together, we compiled the "Technical support plan of difficult village", "Economic development plan" on the basis of investigation and argumentation of the village and the expert group. We highlighted the Long-term poverty alleviation work, had maneuverability and pertinence, made clear from the reality of helping village, seriously analyzed the cause of the poor, formulated the development plan and scheme.

Edible rose was the most main development projects in the village plan of Xi Dian $\mathrm{Zi}$ in Jixian of Tianjin, which was the appropriate local cultivation and good prospects in the market, appropriate local funding technology base, lower production cost and high efficiency.

\section{Probable measures}

Village support for the develop of the aid project implementation plan, detailed support measures to enhance the pertinence of poverty to get rich, is one of the important steps "precise support". According to village and expertise at all levels, the garden planning and design and type selection, configuration, and cultivation management and so on various aspects of information was queried, analyzed and measured for the plan in the field, such as "the layout of the rose garden", "demonstration garden of roses planning", " varieties selection and configuration in varieties nursery ", "nursery planning" and "plantation planning" in the plan of Jixian, which was matched with the corresponding cultivation techniques such as "edible rose cultivation technology", "seedling breed and the introduction of technology", "rose garden planting and management technology", "pest control technology", "rose harvesting and processing technology, storage technology", etc..

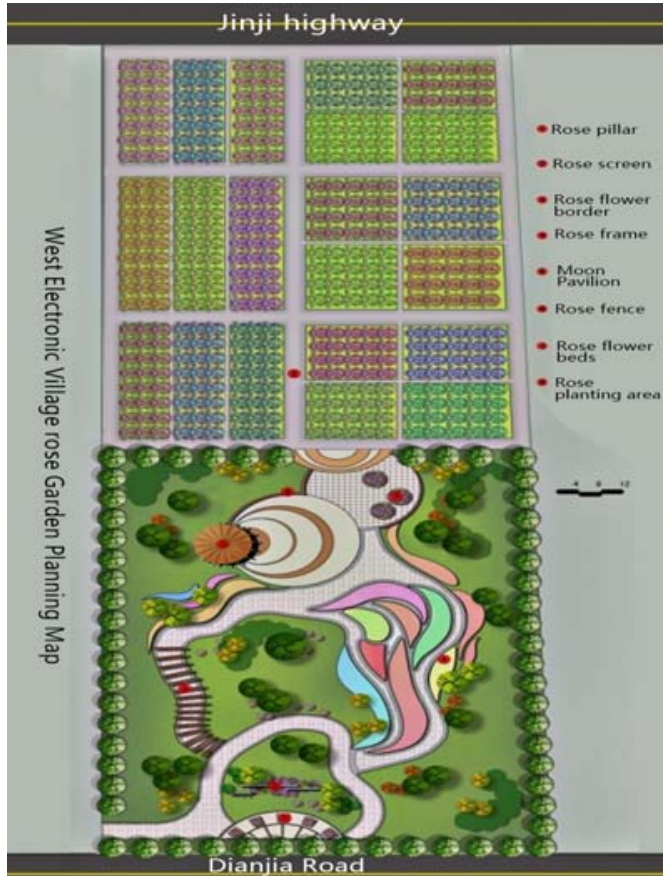

Fig. 1. The village demonstration garden of roses plan in Xi Dian Zhi of Jixian in Tianjin.

\section{SUPPORT TEAM}

The expert group played talent advantage from agricultural university, the leader is given priority in group, "project team" was joint support team to assist.

Tianjin Agricultural College is composed of agriculture, horticulture, garden, animal husbandry and aquatic and other disciplines of the university, with disciplines, experts and more technical expertise and other characteristics

Landscape, animal husbandry and aquaculture of multidisciplinary university, has the subject all, experts, personnel, technology, etc. We was flowers support group of experts, had own team in our university. During the period of support, the team also played the good role, giving full play to the advantages of talents and disciplines. We actively organize the teachers to analyze survey data, someone being good at planning drew the rose garden planning (pictured above), and other was engaged in the construction budget for the project. The team leader carried on the project planning, proposed scheme, selected and configured species and varieties and made implementation.

\section{IV. "EDUCATION" SUPPORT}

Make full use of their own advantages into "education" support through passing knowledge or teaching. Band together long-term goals and short-term mission of fixed-point poverty alleviation work on the basis of the organic combination, focus on improving the key factors which restrict the development of the funding, such as talents, science and technology, industry development and other issues. The village poverty is the key to 
the low production technology level, which could not form a industry. We, as the professor are good at teaching in universities, technical training. Through technical education for poverty alleviation is more important for this village to enhance the "hematopoietic function". We believe, not limited to "blood transfusion", to establish a more effective "blood" mechanism and the advantage of talents in universities and colleges can compensate for this lack of "blood transfusion" incompetent. Poverty alleviation in various fields of the formation of talent pyramid, need from dot to line and from line to plane, from the formation process of surface to the body. When talent pyramid was formed, hematopoietic system is completed.

Based on this, the work should be combined to the actual demand for poverty alleviation, improve the ability of self development as the core, establish long-term education poverty alleviation mechanism using the technology advantage, give full play to the advantages of university experts in education training resources, carry out all-round, multi-level talent intelligence support work. Only build a batch of local professional talent team, give play to the role to transfer effect, can form good self-hematopoietic mechanism, to promote the development of economic and social comprehensive to help the poor village.

\section{V. "NATIVE" SUPPORT}

Combine the superior leader in municipal flower expert group with the local county experts and go on "native" support. We, as a professor at the university supported village team, playing the "think tank" role, to help the development of village industry. Flower expert group, the directors in group leader knew flower industry present situation, problems, market sales situation. Therefore, in determining the direction, planning, and the content of the project, we negotiated with them repeatedly and invited them to go to the village and talked with village cadres and farmers, paid attention to their suggestion, let them advice, technical checks for us. At the same time, we learned modestly from the county experts to understand the local situation (they understood the technology level, management level to local area much more than us), and discussed carefully, negotiated with them, made the plan more "in line with the actual". The work was better combined with the actual situation of the local.

\section{VI. "LINKAGE" SUPPORT}

The first secretary of the village (residency support group leader) was as the axis of "linkage", supported up and down. We went to a few villages, in which the first secretaries of the village were all their residency support leaders. They understood the situation of the village, and had been a period of time with famers, both sides more understood, easy to communicate. Therefore, in most cases we just communicated with the first secretary of the village such as the secretary of the village, and then they charged of communication with local farmers and village head, etc. Effect was better, more likely to reach a consensus.

The establishment of the new rural support mechanism is "government-led, farmers' main body, social support", guided by the scientific outlook on development, on the basis of industrial development, increasing farmers' income as the core, improving the living environment as the key point, promoting agricultural and rural economic work. We shall promote agricultural modernization production technology as the core for poor villages, including the new type of agricultural machinery, modern biological technology, large-scale production technology, etc. "Focus" support promotes the business model that can meet the needs of modern market economy. The business model mainly includes agricultural industrialization, large scale agriculture and agricultural cooperatives and other forms.

Poverty is not only refers to the revenue witch cannot satisfy the lowest life consumption demand, but should also include such as the lack of health, education and living ability, poverty is deprived of the basic feasible abilities. So, some policies should be developed, such as the multidimensional ability support from health, teaching and dwell.

\section{REFERENCES}

[1] Lu Zhang, Jiantao Zhou, The successful experience of poverty alleviation, "Science and technology to assist the whole village ". 2009,(8-2),pp.110-111.

[2] Qingshuang Xiang, Technical support open the door for the farmers to get rich in Shuang Dian,Jiangsu Rural Economy,2014(7),pp.43-44.

[3] Fengxue Dong, The contribution of science and technology support for agricultural production, China Agriculture Information, 2014(12), pp.157-158

[4] Yun Wang, Shu Wang. "four one" pattern analysis in science and technology support of Tianjin [J].Tianjin Agricultural Sciences,2016(8), pp.103-105

[5] Youli Kong. Local investment experts send intellectual support of science and technology to support agriculture of XingHua [J]. Jiangsu Rural Economy,2012(5),pp.66-67.

[6] Changhui Mao. Four patterns in technology support of Jingning [J] China Rural Science \& Technology,2011(2), pp 